\title{
Science and Experience: Repairing a Fractured Medicine
}

\author{
Michael Loughlin \\ European Institute for Person Centred Health and Social Care, School of Biomedical Sciences, University of West \\ London, London, UK
}

\author{
Keywords \\ Scientism · Medicine $\cdot$ History of ideas $\cdot$ Experience $\cdot$ Medical \\ philosophy
}

\section{Wissenschaft und Erfahrung: Wiederherstellung einer frakturierten Medizin}

\section{Schlüsselwörter}

Szientismus · Medizin · Geschichte der Ideen · Erfahrung . Medizinphilosophie

Lionel Milgrom is of course not alone in identifying "scientism" as a serious problem in our thinking about the practice of medicine [1-5]. That said, we need a lot more work like this if we are to generate a broad awareness of the nature of the problem and the pervasiveness of scientistic assumptions. At present, efforts to expose and challenge such assumptions may still be dismissed, either as practically irrelevant philosophical "speculations" and/or indicative of an "anti-science" agenda $[6,7]$. Only by generating an environment in which examining and questioning the scientistic framework is recognised as legitimate and practically relevant can we hope to correct the negative effects of this framework and repair the fractures in medicine created by centuries of unexamined scientism.

So Milgrom is right to identify scientism as a major influence on both current medical practice and education. His claim that scientism "has been allowed to encroach into medicine... via the current form of evidencebased medicine (EBM)" is slightly puzzling, however, since scientism in medicine surely pre-dates the dawn of the EBM movement. If (as Milgrom suggests) EBM has been modified since its initial development in the early 1990s, it is surely the influence of scientism that has facilitated this modification. Milgrom's references to Hume and the rejection of scientism by philosophers of science, including Popper, Kuhn and Quine, suggest he is very well aware how far the debate about science, objectivity, rationality, value, proof, causality and evidence goes back. Indeed, he astutely observes that many scientists "unknowingly" accept the scientism which "as students, they imbibed like 'mother's milk' from their teachers." This is something that has been passed down the generations, often implicitly: it concerns our "underlying assumptions," ideas which frame our everyday reasoning and decision-making and which, almost by definition, we are rarely inclined to bring to the forefront of our thinking and examine critically. This is why Milgrom believes that philosophy should be taught to medical students - it would at least have the advantage of making features of the implicit curriculum explicit, to students and also, perhaps, to some of their teachers.

From the outset, Milgrom characterises scientism in openly pejorative terms as "a pseudo-religious belief in science" which he adds, correctly and importantly, "is itself not scientific." I am grateful that he does attempt to spell out in more substantive terms the content of the belief or doctrine he wishes to criticise - even if this outline is fairly brief and couched in the contextually pejorative language of scientism's "catechism." As I have argued elsewhere, because the term is typically used pejoratively, being characterised as (for instance) the "inappropriate 
employment of scientific methodology or categories in areas better understood in other terms," authors may be reluctant to accept the label "scientism" as applying to their own claims, even when they frame those claims with reference to something they call "the scientific world view" $[4,8]$. Instead, they may be inclined to dismiss critics as having a "philosophical agenda," as though one set of underlying assumptions about the nature and role of science counts as a philosophy (and by implication can therefore be dismissed as "practically irrelevant" [6]) while their own set of assumptions requires no justification, being just "sheer common sense." In fact, where two incompatible frameworks make a difference to practice, it is imperative to understand the differences between them, their underlying rationales and implications, so that one can come to an informed conclusion regarding which (if either) is preferable. To fail to do so is to allow one's ideas, dispositions and consequently one's behaviour to be determined by forces one fails even to perceive, let alone control [9] - an approach hardly characteristic of the autonomous, rational professional.

In the first instance, then, we need to spell out the substance of scientism, how it functions to "frame" medical practice and possible alternative ways of framing such practice. We need a definition of scientism that does not automatically amount to an accusation [4], if we are to understand why its influence is so widespread, affecting the dialogue and practices of so many highly intelligent people.

What is more, we need to be clear to the point of pedantry on a particular point: that scientism is not science, nor is it a scientific theory. Rather, it is a philosophical theory about science, its nature and relationship with other forms of knowing and reasoning. To be against scientism is not to be anti-science. Quite the reverse: the logic of scientism needs to be rejected if we are to defend the value of science, at a time when trust in science is being wilfully undermined by powerful forces in this dangerous "post-truth" era [10, 11].

Milgrom characterises the substance of scientism by spelling out three crucial claims:

1. Only scientific knowledge may be classed as real knowledge

2. There is no rational, objective form of inquiry that is not science

3. Science is the absolute and only justifiable access to truth

This explains the dismissal of the humanities ${ }^{1}$, including philosophy [6] on the part of some of sci-

\footnotetext{
See for instance Goldacre's use of the term "humanities graduate" as a form of abuse [12].

For a fuller exposition see Loughlin et al. [4].

A body is defined as that which has "extension": its essence is simply that it fills up space.
}

entism's strident exponents - a dismissal which, Milgrom notes (citing Popper) renders scientism self-refuting. It is not a scientific theory (but rather a philosophical theory about science) and so, given its own accounts of knowledge and truth, cannot count as knowledge or claim to be true.

How, then, has it survived so long and had such a profound influence on practice? To understand this requires doing something most defenders of scientism would deem unworthy of their attention and time: studying the history of ideas. As any good philosophy graduate knows, Descartes is sometimes referred to as "the father of modern philosophy" in that his work brilliantly embodies the essential features of the distinctly modern world view [13]. Unlike the ancients, Descartes postulated a series of absolute dichotomies, his metaphysical dualism dividing the world into "subjective" and "objective" realms, with the former containing human experience and value, and the latter consisting of measurable material objects and properties, the stuff of mind-independent reality. ${ }^{2}$ While morality and aesthetics, along with all things qualitative (phenomenal properties, goals, desires, emotions and our "inner" perceptions, pleasures and pains) are understood via the faculty of "introspection," it is the job of science to investigate the nature of "external reality," to map this realm of objective causes and effects and to measure its properties, with the goal of providing a complete description of the world of "body," a term used interchangeably with "matter" in Cartesian discourse. ${ }^{3}$

This philosophy provided the ideal conceptual framework for the emerging industrial era, encouraging a focus on the quantification of observable features of the physical world which undoubtedly helped fuel advances in numerous areas. In medical research, the Cartesian concept of the "man machine" [13] - an explicit rejection of Aristotle's teleological understanding of the human body and its reconceptualisation as a "complex mechanism" - inspired extensive advances in anatomy and physiology. Though the experience of pain was not part of the "external world," and so did not fall under the remit of "objective science," the causal mechanisms of pain most certainly did. Again, it would be facile for opponents of scientism (such as Milgrom and myself) to deny that this framework led to significant progress in our understanding of the body, but by doing so we in no way concede that the framework is correct, or that we do not now need to revive insights from the ancients (including Hippocrates and Aristotle) that have been forgotten or sidelined in the modern era. The radical separation of "mind" and "body" came at a price: human life and its defining features, including awareness, engagement and agency, become inherently problematic ideas. Our natural awareness of our own activities is holistic: I experience myself making 
choices, moving around as a complete organism, directly aware of and interacting with the objects of my experience in the real world. But given scientism's conception of the "real world," organisms are "really" mechanisms, while "choices" and "actions" have no place in a world where there are only events, subject to the laws of mechanistic cause and effect. The primary object of medical investigation, the living human being, becomes a metaphysical oddity, straddling two incompatible metaphysical realms.

Whatever its advantages with regard to focusing attention in particular areas of study, a theoretical framework that renders the previously straightforward inherently problematic is clearly not an unequivocal advance. Scientism fractures the subject of proper medical attention. Subsequent exponents of scientism "solved" this problem by denying the reality of the subjective side of the Cartesian picture, replacing his dualism with some form of reductionism. Such authors insist that the "objective" world (understood, note, in scientistic terms, as something containing no phenomenal properties, no value, only causes and effects as understood in reductionist science) is all there really is [4]. There is no gap to be bridged between the subjective and the objective features of human life, because the objective features are the only ones that exist. Thus we see distinguished philosophers going to great lengths to explain why they are not (appearances to the contrary) quite literally denying the obvious, such as the experiences we have when we open our eyes, or indeed think or feel anything at all [14]. Those of us who reject scientism fail to see how one solves the problem of having fractured our lived reality by depositing one side of the fracture in the philosophical waste bin.

Again risking clarification to the point of pedantry, this is not a rejection of science, or even of the philosophy sometimes called "scientific realism." We are not denying that science reveals aspects of reality that are not revealed in everyday experience. We are simply disinclined to go further, to join scientism's exponents in claiming that the scientific enquiry replaces (rather than enhances) our everyday awareness of the facts of our own lives, revealing the true "essence" of reality and rendering our "everyday talk" of objects and experiences "ontologically redundant" [15]. For instance, thanks to the science of neurology, we now know that certain brain states are necessary if human emotion is even to be possible. However, we see no need to go further and say that the neurological account gives us the complete and final description of what these emotions "really are" [16]. If Caroline feels unhappy then she knows something about her current state of unhappiness, and anyone examining a brain scan is surely at least as reliant upon the knowledge Caroline supplies as she is upon their insights. Yet the dominance of scientism means that we need to argue a case for taking such ideas as "patient expertise" seriously $[17,18]$. Science and practice are indeed "corrupted" when what should be just plain obvious is treated as "unscientific."

What we need is a new starting point. We should not (as some sceptics and postmodernists would do) surrender the concepts of objectivity, rationality, knowledge and proof to the scientistic camp, ostensibly rejecting scientism by denying there is any such thing as "objectivity" and the rest [5]. To do that is to implicitly accept the logic of scientism, and while it might provoke potentially amusing outrage amongst some scientistic authors [19] it does little to help us reframe our thinking. As Milgrom notes, Hume applied the sceptical aspects of scientism's account of reasoning (the absolute divide between rationality and trust or "naivety") to argue that only conclusions that followed deductively from direct observation could be proven - from which he concluded that no scientific propositions could be proved. Indeed, the "naive inductivism" that is the basis for our assumption that the sun will rise tomorrow (in the absence of evidence to the contrary) is itself unproven and therefore non-rational [1]. If a practising scientist is able to find her way to the laboratory in the morning, let alone conclude that any experiments she did yesterday give her any basis for conclusions about what she might observe today, then she needs to reject this conception of proof.

Science is a human activity. If human experience does not give us access to reality, then neither will it do so in the context of scientific investigation. We need a revised conception of medical and scientific reasoning which understands the latter as an aspect of a broader, humanistic conception of reasoning. Milgrom's work is to be welcomed as part of this ongoing and important project.

\section{Conflict of Interest Statement}

The author has no conflicts of interest to declare.

References

Milgrom L. Against scientism: corrupted science and the fight for medicine's soul. Complement Med Res. 2020. DOI: 10.1159/000510229. Epub.

2 Leggett JM. Medical scientism: good practice or fatal error? J R Soc Med. 1997 Feb;90(2): 97-101.

3 Haack S. Defending science within reason: Between scientism and cynicism. Amherst: Prometheus Books; 2003.

4 Loughlin M, Lewith G, Falkenberg T. Science, practice and mythology: a definition and examination of the implications of scientism in medicine. Health Care Anal. 2013 Jun;21(2): 130-45. 
5 Loughlin M. Reason, reality and objectivityshared dogmas and distortions in the way both 'scientistic' and 'postmodern' commentators frame the EBM debate. J Eval Clin Pract. 2008 Oct;14(5):665-71.

6 Why philosophy is largely ignored by science: http://www.dcscience.net/2011/10/28/whyphilosophy-is-largely-ignored-by-science/ (accessed May 8, 2015)

7 Loughlin M, Bluhm R, Gupta M. Research problems and methods in the philosophy of medicine. In: Marcum J, editor. The Bloomsbury companion to contemporary philosophy of medicine. London: Bloomsbury; 2017. Chapter 2, p. 29-62.

8 Dennett D. Breaking the spell. New York: Penguin Books; 2006.

9 Loughlin M. Ethics, management and mythology. Oxford: Radcliffe Medical Press; 2002
10 Goldenberg MJ. Whose social values? Evaluating Canada's 'death of evidence' controversy. Can J Philos. 2015;45(3):404-24.

11 Kakutani M. The death of truth: how we gave up on facts and ended up with Trump. The Guardian, July 14, 2018.

12 Goldacre B. Objectionable "objectives." The Guardian, August 19, 2006 [cited 2007 Jun 28]. Available from: http://www.guardian. co.uk/life/badscience/story/0,1853711,00. html

13 Anscombe E, Geach PT. Descartes' philosophical writings. London: Thomas Nelson and Sons; 1954.

14 Dennett D. Illusionism as the obvious default theory of consciousness. J Conscious Stud. 2016;23:65-72.
15 Baker LR. A metaphysics of ordinary things and why we need it. Philosophy. 2008;83(1): 5-24.

16 Griffiths PE. What emotions really are. Chicago: University of Chicago Press; 1998.

17 Yelovich MC. The patient-physician interaction as a meeting of experts: one solution to the problem of patient non-adherence. J Eval Clin Pract. 2016 Aug;22(4):558-64.

18 Walach H, Loughlin M. Patients and agents - or why we need a different narrative: a philosophical analysis. Philos Ethics Humanit Med. 2018 Oct;13(1):13.

19 Loughlin M. Style, substance, Newspeak 'and all that': a commentary on Murray et al. (2007) and an open challenge to Goldacre and other 'offended' apologists for EBM. J Eval Clin Pract. 2007 Aug;13(4):517-21. 